\title{
Leslie J.-R. Péan, Haïti, économie politique de la corruption. De Saint-Domingue à Haïti 1791-1870
}

\section{Maria Chiara Gnocchi}

\section{(2) OpenEdition}

1 Journals

\section{Édition électronique}

URL : https://journals.openedition.org/studifrancesi/38453

DOI : $10.4000 /$ studifrancesi.38453

ISSN : 2427-5856

Éditeur

Rosenberg \& Sellier

\section{Édition imprimée}

Date de publication : 15 décembre 2004

Pagination : 660

ISSN : 0039-2944

\section{Référence électronique}

Maria Chiara Gnocchi, « Leslie J.-R. Péan, Haiti, économie politique de la corruption. De Saint-Domingue à Haïti 1791-1870», Studi Francesi [En ligne], 144 (XLVIII | III) | 2004, mis en ligne le 30 novembre 2015, consulté le 08 mai 2021. URL : http://journals.openedition.org/studifrancesi/38453 ; DOI : https:// doi.org/10.4000/studifrancesi.38453

Ce document a été généré automatiquement le 8 mai 2021.

\section{(c) $(1) \odot$}

Studi Francesi è distribuita con Licenza Creative Commons Attribuzione - Non commerciale - Non opere derivate 4.0 Internazionale. 


\title{
Leslie J.-R. Péan, Haïti, économie politique de la corruption. De Saint- Domingue à Haïti 1791-1870
}

\author{
Maria Chiara Gnocchi
}

\section{RÉFÉRENCE}

LESLIE J.-R. PÉAN, Haïti, économie politique de la corruption. De Saint-Domingue à Haïti 1791-1870, préface de J. CHEVRIER, Paris, Maisonneuve \& Larose, 2003 ("Littératures d'Afrique et de la Caraïbe"), pp. 348.

1 Haïtien s'étant formé en France puis aux États-Unis, Leslie J.-R. Péan travaille actuellement à la Banque Mondiale à Washington. C'est dans ces connaissances et compétences multiples que trouve ses fondements cette imposante analyse-réquisitoire parue aux éditions Maisonneuve \& Larose. S'étant fixé le but d'éclairer le présent et de le comprendre par l'étude du passé, Péan parcourt l'histoire nationale haïtienne de ses origines à 1870 (un second volet est prévu, couvrant la période qui s'étend de 1870 à nos jours) pour démontrer comment la corruption s'est institutionnalisée en Haïti, affectant non seulement les pratiques financières, mais également la fonction publique et le pouvoir juridique. La source du mal remonte certainement à l'expérience traumatisante de la colonisation, ce qui ne permet pas pour autant d'exonérer de toute responsabilité des dynasties de dirigeants qui ont perpétué et multiplié des formes de violence et d'injustice pour ainsi dire officielles. Si la corruption procède selon une logique rigoureuse, c'est à travers une opération tout autant rigoureuse que l'auteur se propose de la comprendre et de l'illustrer; une opération qui relève de l'économie politique au sens où l'entend Foucault, c'est-à-dire en tant que "réflexion sur l'organisation, la distribution et la limitation des pouvoirs dans une société".

2 Jacques Chevrier, signataire de la préface, met l'accent sur quatre pôles d'intérêt qu'il dégage du vaste et complexe panorama proposé par Leslie J.-R. Péan: l'instabilité 
chronique du pouvoir d'Haïti et "son irrépressible tropisme totalitaire"; le poids de l'héritage colonial; la tension omniprésente entre noirs et mulâtres qui s'alternent sur la scène politique; enfin l'importance de la pratique du Vaudou dans sa relation au pouvoir. Le volume se termine par une série de quatre annexes et par une bibliographie importante qui compte près de 20 pages. 